\title{
Acceptance of Telerheumatology by Rheumatologists and General Practitioners in Germany: Nationwide Cross-sectional Survey Study
}

Felix Muehlensiepen ${ }^{1,2,3}$, MPH, Dr rer medic; Johannes Knitza ${ }^{4}$, MHBA, Dr med; Wenke Marquardt ${ }^{1}$, MSc; Jennifer Engler ${ }^{5}$, MPH, MA, Dr rer medic; Axel Hueber ${ }^{6}$, Dr med, PhD; Martin Welcker ${ }^{7}$, Dr med

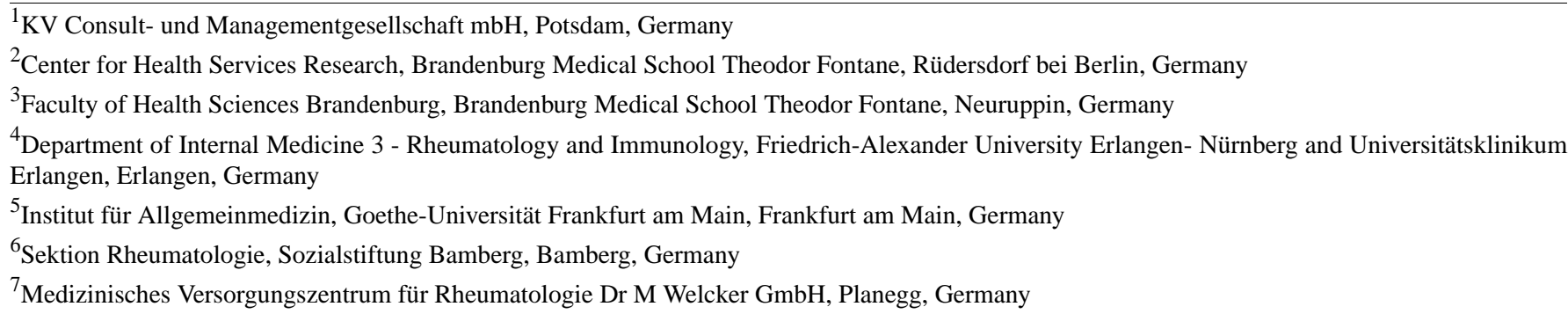

\section{Corresponding Author:}

Felix Muehlensiepen, MPH, Dr rer medic

Center for Health Services Research

Brandenburg Medical School Theodor Fontane

Seebad 82/83

Rüdersdorf bei Berlin, 15562

Germany

Phone: 493363883501

Email: Felix.Muehlensiepen@mhb-fontane.de

\section{Abstract}

Background: The worldwide burden of musculoskeletal diseases is increasing. The number of newly registered rheumatologists has stagnated. Primary care, which takes up a key role in early detection of rheumatic disease, is working at full capacity. COVID-19 and its containment impede rheumatological treatment. Telemedicine in rheumatology (telerheumatology) could support rheumatologists and general practitioners.

Objective: The goal of this study was to investigate acceptance and preferences related to the use of telerheumatology care among German rheumatologists and general practitioners.

Methods: A nationwide, cross-sectional, self-completed, paper-based survey on telerheumatology care was conducted among outpatient rheumatologists and general practitioners during the pre-COVID-19 period.

Results: A total of $73.3 \%$ (349/476) of survey participants rated their knowledge of telemedicine as unsatisfactory, poor, or very poor. The majority of survey participants $(358 / 480,74.6 \%)$ answered that they do not currently use telemedicine, although $62.3 \%$ (291/467) would like to. Barriers to the implementation of telemedicine include the purchase of technology equipment $(182 / 292,62.3 \%)$, administration $(181 / 292,62.0 \%)$, and poor reimbursement $(156 / 292,53.4 \%)$. A total of $69.6 \%$ (117/168) of the surveyed physicians reckoned that telemedicine could be used in rheumatology. Surveyed physicians would prefer to use telemedicine to communicate directly with other physicians $(370 / 455,81.3 \%)$ than to communicate with patients $(213 / 455$, $46.8 \%$ ). Among treatment phases, 64.4\% (291/452) of participants would choose to use telemedicine during follow-up. Half of the participants would choose telecounseling as a specific approach to improve rheumatology care $(91 / 170,53.5 \%)$.

Conclusions: Before COVID-19 appeared, our results indicated generally low use but high acceptance of the implementation of telerheumatology among physicians. Participants indicated that the lack of a structural framework was a barrier to the effective implementation of telerheumatology. Training courses should be introduced to address the limited knowledge on the part of physicians in the use of telemedicine. More research into telerheumatology is required. This includes large-scale randomized controlled trials, economic analyses, and the exploration of user preferences. 
(J Med Internet Res 2021;23(3):e23742) doi: 10.2196/23742

\section{KEYWORDS}

telemedicine; eHealth; mHealth; rheumatology; primary care; health services research; COVID-19

\section{Introduction}

The worldwide burden of musculoskeletal diseases is increasing

[1]. Growing life expectancy, widespread overweight, and a frequent lack of exercise have caused a surge in musculoskeletal disorders. Besides individual health burden, these chronic diseases create a considerable financial burden for society overall, as patients often take sick leave and early retirement [2]. While increasingly effective treatments have been developed and implemented, the number of newly registered rheumatologists has stagnated [3], and the global need for rheumatologists cannot be met [4]. General practitioners are usually the first point of contact for patients and play an important role in the early detection of rheumatic and musculoskeletal diseases (RMDs). But primary care is also affected by a shortage of staff and, in view of demographic change, an increasingly demanding work burden [5,6]. A lack of physicians has led to diagnostic delays for various rheumatologic diseases [7] and a decrease in treatment efficacy [8].

In recent decades, information and communication technologies have entered health care. One field of application is telemedicine, which is defined as follows [9]:

Telemedicine is the practice of medicine over a distance, in which interventions, diagnoses, therapeutic decisions, and subsequent treatment recommendations are based on patient data, documents and other information transmitted through telecommunication systems.

The use of telemedicine in the provision of rheumatology care (telerheumatology) could ease constraints on health care access and the timeliness of care, bridge the workforce gap, and improve access to care for underserved communities [10,11]. The effectiveness of telerheumatology could be equal or higher than a standard face-to-face approach [12-16]. However, evidence is lacking, and further studies are needed to determine the best use of telerheumatology [16,17]. The current global COVID-19 pandemic has highlighted the need for telerheumatology and could promote the use of innovative solutions in clinical routines [18]. However, the effective implementation of telerheumatology requires acceptance by potential users.

The aim of this user-centered study was to assess the acceptance by physicians of the implementation of telerheumatology and to identify potential application areas in preparation for the development of telemedical approaches.

\section{Methods}

This paper reports on findings from the analysis of data collected as part of a cross-sectional, self-completed, paper-based survey of German outpatient rheumatologists and general practitioners from September to November 2018; the survey investigated acceptance, opportunities, and obstacles to the implementation of telemedicine.

The inclusion criteria for participants were that they had to be (1) rheumatologists or general practitioners, (2) practicing in ambulatory health care, (3) based in Germany, and (4) active (ie, not retired and not in training).

Two health care researchers (FM and WM) and one experienced rheumatologist (MW) designed the questionnaire. It was pilot-tested on 5 rheumatologists and 5 general practitioners to gauge the need to refine wording and format, and to check whether predefined response options were exhaustive. Minor revisions were made accordingly.

The questionnaire comprised 25 questions and was divided into three mandatory sections:

1. Telemedicine: knowledge and use.

2. Telerheumatology.

3. Sociodemographic data.

Response categories were nominal or ordinal. The questionnaire also contained several open questions.

The telemedicine: knowledge and use section included questions about expertise and the use of telemedicine. Participants were asked to rate their knowledge of telemedicine on a 6-point Likert scale. Furthermore, inquiries were made into current telemedicine use, willingness to use telemedicine, and barriers to its use.

The telerheumatology section included questions about the perceived usefulness of telerheumatology. This section also included questions about preferences for particular uses of telerheumatology, such as patient groups, application areas, and specific tools.

Questions about sociodemographic and occupational characteristics included age, gender, medical specialty, clinical location, type of practice, and number of patients (quarterly).

The survey was sent to all rheumatologists $(n=49)$ and general practitioners $(n=1820)$ in the federal state of Brandenburg, Germany, and rheumatologists $(\mathrm{n}=39)$ and general practitioners $(n=487)$ in a nationwide reference group. The contact details of potential participants in Brandenburg were provided by the Brandenburg Association of Statutory Health Insurance Physicians. The nationwide reference group consisted of physicians from RHADAR (RheumaDatenRhePort GbR) and cooperating rheumatologists and general practitioners. RHADAR is an association of more than 25 rheumatologists that share the aim of developing and improving digital technology. The association also collects and analyzes anonymized patient data to identify supply and demand for rheumatology services. In total, 88 rheumatologists and 2307 general practitioners were contacted by mail. 
Statistical analyses were performed using SPSS Statistics for Windows, version 22.0 (IBM Corp). Descriptive statistics included quantities, percentages, median scores, and ranges for ordinal variables.

The study was conducted in compliance with current data protection regulations and the Helsinki Declaration. All study participants were informed about the research project. Data were anonymized before analysis. The ethics committee of the Theodor Fontane Medical School in Brandenburg stated that no written consent was necessary due to the noninterventional study design.

\section{Results}

\section{Overview}

From September to November 2018, a cross-sectional, self-completed, paper-based survey on telerheumatology was filled in by German outpatient rheumatologists and general practitioners. Of the 2395 questionnaires that were sent out, 497
(20.8\%) were returned. Of the 497 responses, 12 (2.4\%) were excluded from the analysis because fewer than half the questions were answered. The final response rate for rheumatologists was $55 \%(48 / 88)$ and for general practitioners it was $18.9 \%$ (437/2307).

\section{Sample Characteristics}

Data for this study were obtained from 485 physicians (437/485, 90.1\% general practitioners; 48/485, 9.9\% rheumatologists) (see Table 1). About half of the respondents were between 50 and 60 years old $(228 / 474,48.1 \%)$. Slightly more than half of the participants were women $(254 / 470,54.0 \%)$. One-third of the surveyed physicians worked in a town $(154 / 474,32.5 \%)$, one-third worked in a provincial town (158/474, 33.3\%), 17.9\% $(85 / 474)$ worked in a city, and $16.2 \%(77 / 474)$ worked in a rural area. Overall, 53.5\% (252/471) of the physicians worked in a single-handed practice and 46.5\% (219/471) worked in a group practice. Almost two-thirds of the surveyed physicians treated over 4000 patients per year.

Table 1. Participant demographics.

\begin{tabular}{|c|c|c|c|c|}
\hline Demographic & Rheumatologists, $\mathrm{n}(\%)^{\mathrm{a}}$ & General practitioners, $\mathrm{n}(\%)^{\mathrm{a}}$ & $P$ value & Total, $\mathrm{n}(\%)^{\mathrm{a}}$ \\
\hline \multicolumn{5}{|l|}{ Age (years) } \\
\hline Total & $47(100)$ & $427(100)$ & .22 & $474(100)$ \\
\hline$<40$ & $4(9)$ & $36(8.4)$ & & $40(8.4)$ \\
\hline $40-50$ & $16(34)$ & $85(19.9)$ & & $101(21.3)$ \\
\hline $51-60$ & $20(43)$ & $208(48.7)$ & & $228(48.1)$ \\
\hline$>60$ & $7(15)$ & $98(23.0)$ & & $105(22.2)$ \\
\hline \multicolumn{5}{|l|}{ Gender } \\
\hline Total & $46(100)$ & $424(100)$ & .17 & $470(100)$ \\
\hline Female & $19(41)$ & $235(55.4)$ & & $254(54.0)$ \\
\hline Male & $27(59)$ & $189(44.6)$ & & $216(46.0)$ \\
\hline \multicolumn{5}{|l|}{ Clinical location } \\
\hline Total & $47(100)$ & $427(100)$ & $<.001$ & $474(100)$ \\
\hline City & $23(49)$ & $62(14.5)$ & & 85 (17.9) \\
\hline Town & $10(21)$ & $144(33.7)$ & & $154(32.5)$ \\
\hline Provincial town & $14(30)$ & $144(33.7)$ & & $158(33.3)$ \\
\hline Rural area & $0(0)$ & $77(18.0)$ & & $77(16.2)$ \\
\hline \multicolumn{5}{|l|}{ Type of practice } \\
\hline Total & $47(100)$ & $424(100)$ & $<.001$ & $471(100)$ \\
\hline Single-handed & $10(21)$ & $242(57.1)$ & & $252(53.5)$ \\
\hline Group & $37(79)$ & $182(42.9)$ & & $219(46.5)$ \\
\hline \multicolumn{5}{|c|}{ No. of patients treated (quarterly) } \\
\hline Total & $45(100)$ & $411(100)$ & .14 & $456(100)$ \\
\hline$<500$ & $4(9)$ & $15(3.6)$ & & $19(4.2)$ \\
\hline $500-1000$ & $17(38)$ & $130(31.6)$ & & $147(32.2)$ \\
\hline$>1000$ & $24(53)$ & $266(64.7)$ & & $290(63.6)$ \\
\hline
\end{tabular}

${ }^{\text {a }}$ Percentages may not add up to $100 \%$ due to rounding. 


\section{Telemedicine: Knowledge and Use}

A total of $73.3 \%$ (349/476) of respondents rated their knowledge of telemedicine as 4 (unsatisfactory), 5 (poor), or 6 (very poor). The minority $(127 / 476,26.7 \%)$ rated their knowledge of telemedicine as 1 (very good), 2 (good), or 3 (satisfactory). The majority $(358 / 480,74.6 \%)$ did not currently use telemedicine, but $62.3 \%$ (291/467) answered that they would like to use it (see Table 2). A total of $89.3 \%$ (259/290) of surveyed physicians indicated that barriers prevented them from using telemedicine. The top three obstacles to the introduction of telemedicine according to respondents were the purchase of technology equipment $(182 / 292,62.3 \%)$, administration $(181 / 292,62.0 \%)$, and inadequate remuneration $(156 / 292,53.4 \%)$.

Table 2. Telemedicine: knowledge and use.

\begin{tabular}{|c|c|c|c|c|}
\hline Question and responses & Rheumatologists, $\mathrm{n}(\%)^{\mathrm{a}}$ & General practitioners, $\mathrm{n}(\%)^{\mathrm{a}}$ & $P$ value & Total, $\mathrm{n}(\%)^{\mathrm{a}}$ \\
\hline \multicolumn{5}{|c|}{ How do you rate your own knowledge of telemedicine? } \\
\hline Total & $47(100)$ & $429(100)$ & .14 & $476(100)$ \\
\hline 1 (very good) & $1(2)$ & $19(4.4)$ & & $20(4.2)$ \\
\hline 2 (good) & $8(17)$ & $34(7.9)$ & & $42(8.8)$ \\
\hline 3 (satisfactory) & $9(19)$ & $56(13.1)$ & & $65(13.7)$ \\
\hline 4 (unsatisfactory) & $9(19)$ & $110(25.6)$ & & $119(25.0)$ \\
\hline 5 (poor) & $16(34)$ & $138(32.2)$ & & $154(32.4)$ \\
\hline 6 (very poor) & $4(9)$ & $72(16.8)$ & & $76(16.0)$ \\
\hline \multicolumn{5}{|l|}{ Do you use telemedicine? } \\
\hline Total & $47(100)$ & $433(100)$ & .15 & $480(100)$ \\
\hline Yes & $16(34)$ & $106(24.5)$ & & $122(25.4)$ \\
\hline No & $31(66)$ & $327(75.5)$ & & $358(74.6)$ \\
\hline \multicolumn{5}{|l|}{ Would you like to use telemedicine? } \\
\hline Total & $46(100)$ & $421(100)$ & .45 & $467(100)$ \\
\hline Yes & $31(67)$ & $260(61.8)$ & & $291(62.3)$ \\
\hline No & $15(33)$ & $161(38.2)$ & & $176(37.7)$ \\
\hline \multicolumn{5}{|c|}{ Does anything prevent you from using telemedicine? } \\
\hline Total & $30(100)$ & $260(100)$ & .26 & $290(100)$ \\
\hline Yes & $25(83)$ & $234(90.0)$ & & $259(89.3)$ \\
\hline No & $5(17)$ & $26(10.0)$ & & $31(10.7)$ \\
\hline \multicolumn{5}{|c|}{ What prevents you from using telemedicine? (multiple selections possible) } \\
\hline Total & $31(100)$ & $261(100)$ & & $292(100)$ \\
\hline Purchase of technology equipment & $16(52)$ & $166(63.6)$ & .19 & $182(62.3)$ \\
\hline Administration & $21(68)$ & $160(61.3)$ & .49 & $181(62.0)$ \\
\hline Poor reimbursement & $21(68)$ & $135(51.7)$ & .09 & $156(53.4)$ \\
\hline Data security & $15(48)$ & $120(46.0)$ & .80 & $135(46.2)$ \\
\hline Lack of participation by colleagues & $8(26)$ & $89(34.1)$ & .35 & $97(33.2)$ \\
\hline Technical comprehension of patients & $12(39)$ & $84(32.3)$ & .47 & $96(32.9)$ \\
\hline Poor internet connection & $5(16)$ & $52(19.9)$ & .61 & $57(19.5)$ \\
\hline
\end{tabular}

${ }^{\mathrm{a}}$ Percentages may not add up to $100 \%$ due to rounding or where multiple selections were possible.

\section{Implementation of Telerheumatology}

A total of $69.6 \%(117 / 168)$ of participants considered telemedicine as usable in rheumatology (see Table 3).

When asked who should interact using telemedicine, $81.3 \%$ (370/455) responded physician-physician, 46.8\% (213/455) responded physician-patient, and $25.7 \%$ (117/455) responded physician-assistant (multiple replies were possible). The preferred therapy phases for the use of telemedicine were follow-up (291/452, 64.4\%), initial contact (153/452, 33.8\%), and screening $(133 / 452,29.4 \%)$. Participants were asked to indicate specific digital tools that could support rheumatology care. The most frequently selected items were telecounseling $(91 / 170,53.5 \%)$, telediagnostics $(76 / 170,44.7 \%)$, and video 
consultations $(67 / 170,39.4 \%)$. These were followed by online appointment assignments (56/170, 32.9\%), e-learning (55/170, $32.4 \%)$, patient apps $(48 / 170,28.2 \%)$, digital screening $(36 / 170$,
$21.2 \%)$, wearable devices $(20 / 170,11.8 \%)$, telesurgery $(7 / 170$, $4.1 \%)$, and other tools $(4 / 170,2.4 \%)$.

Table 3. Implementation of telemedicine in rheumatology care.

\begin{tabular}{|c|c|c|c|c|}
\hline Question and responses & Rheumatologists, $\mathrm{n}(\%)^{\mathrm{a}}$ & General practitioners, $\mathrm{n}(\%)^{\mathrm{a}}$ & $P$ value & Total, $\mathrm{n}(\%)^{\mathrm{a}}$ \\
\hline \multicolumn{5}{|l|}{ Is telemedicine usable in rheumatology? } \\
\hline Total & $43(100)$ & $125(100)$ & .18 & $168(100)$ \\
\hline Yes & $32(74)$ & $85(68.0)$ & & $117(69.6)$ \\
\hline No & $11(26)$ & $40(32.0)$ & & $51(30.4)$ \\
\hline \multicolumn{5}{|c|}{ Which parties should establish communication via telemedicine? (multiple selections possible) } \\
\hline Total & $45(100)$ & $410(100)$ & & $455(100)$ \\
\hline Physician-physician & $36(80)$ & $334(81.5)$ & .88 & $370(81.3)$ \\
\hline Physician-patient & $28(62)$ & $185(45.1)$ & .03 & $213(46.8)$ \\
\hline Physician-assistant & $14(31)$ & $103(25.1)$ & .38 & $117(25.7)$ \\
\hline Other participants and combinations & $5(11)$ & $13(3.2)$ & .009 & $18(4.0)$ \\
\hline No communication & $3(7)$ & $54(13.2)$ & .21 & $57(12.6)$ \\
\hline \multicolumn{5}{|c|}{ At which stages can telemedicine support rheumatology care? (multiple selections possible) } \\
\hline Total & $45(100)$ & $407(100)$ & & $452(100)$ \\
\hline Screening & $23(51)$ & $110(27.0)$ & .001 & $133(29.4)$ \\
\hline Initial contact & $11(24)$ & $142(34.9)$ & .16 & $153(33.8)$ \\
\hline Follow-up & $32(71)$ & $259(63.6)$ & .32 & $291(64.4)$ \\
\hline Other stages & $7(16)$ & $38(9.4)$ & .19 & $45(10.0)$ \\
\hline At no stage & $8(18)$ & $69(17.0)$ & .90 & $77(17.1)$ \\
\hline \multicolumn{5}{|c|}{ Which tools could support rheumatologic care? (multiple selections possible) } \\
\hline Total & $44(100)$ & $126(100)$ & & $170(100)$ \\
\hline Telecounseling & $24(55)$ & $55(43.7)$ & .21 & $79(45.5)$ \\
\hline Telediagnostics & $18(41)$ & $58(46.0)$ & .56 & $76(44.7)$ \\
\hline Video consultations & $19(43)$ & $48(38.1)$ & .55 & $67(39.4)$ \\
\hline Online appointment assignments & $20(45)$ & $36(28.6)$ & .04 & $56(32.9)$ \\
\hline e-Learning & $15(34)$ & $40(31.7)$ & .78 & $55(32.4)$ \\
\hline Patient apps & $17(39)$ & 31 (24.6) & .08 & $48(28.2)$ \\
\hline Digital screening & $15(34)$ & $21(16.7)$ & .02 & $36(21.2)$ \\
\hline Wearable devices & $9(20)$ & $11(8.7)$ & .04 & $20(11.8)$ \\
\hline Telesurgery & $3(7)$ & $4(3.2)$ & .30 & $7(4.1)$ \\
\hline Other tools & $2(5)$ & $2(1.6)$ & .27 & $4(2.4)$ \\
\hline No tools & $6(14)$ & 15 (11.9) & .76 & $21(12.4)$ \\
\hline
\end{tabular}

${ }^{\mathrm{a}}$ Percentages do not add up to $100 \%$ where multiple selections were possible.

\section{Discussion}

\section{Principal Findings}

To the best of our knowledge, we have performed the largest nationwide survey in Germany on the use of telemedicine in adult rheumatology aimed at promoting and guiding the implementation of telerheumatology.
Rheumatologists and general practitioners generally consider the overall application of telerheumatology to be acceptable, and two-thirds of the respondents would like to implement telemedicine in their everyday practice. Rheumatologists expressed an even greater willingness to use telemedicine than general practitioners. Rheumatologists and general practitioners welcomed a wide variety of approaches to telemedicine. However, only a minority of physicians already used 
telemedicine at the time the survey was conducted. Barriers to its introduction, such as limited knowledge, administrative expenses, the purchase of technology equipment, and inadequate reimbursement, were clearly identified by specialists and generalists. The results provide information on how telemedicine can support rheumatology care from the physician's perspective. Conservative and familiar communication formats, such as the exchange of information with colleagues, were preferred to the direct exchange of information with patients and assistants. This was demonstrated by the high approval of the item telecounseling. Although various telecounseling tools already exist, their development for rheumatology applications is not as advanced as in, for example, intensive care and cardiology. This is reflected in the relatively small number of respondents that were using telemedicine at the time of the survey.

\section{Limitations}

The average age of our sample is similar to that of German physicians as a whole [19]. Women were slightly overrepresented compared to the average [19], which may also indicate that female physicians are more interested in telehealth. Due to the small number of rheumatologists, this survey mainly reports on the opinion of general practitioners. Although the survey was directed at physicians from all over Germany, it was primarily physicians from Brandenburg who participated due to the recruitment strategy. We assume a self-selection bias and a nonresponse bias, as the survey was probably mainly answered by physicians who are interested in telemedicine and rheumatology. To overcome this bias, we chose a paper-based survey. An online survey may have increased the response rate and reduced the effort for data management. However, we assumed an online survey would have influenced response behavior, in the sense of a positive bias toward users of telemedicine. To answer the questionnaire, knowledge in the field of telemedicine was required, as, for example, preferences for specific tools were asked about. Considering the limited knowledge of doctors in the field of telemedicine, response biases are, therefore, likely. Furthermore, we assume that due to rapid technical developments in the field, our predefined response categories were not exhaustive. Only ambulatory physicians were asked to participate in the survey, so the results do not provide any information on the acceptance by patients, hospital staff, or other professional groups other than outpatient physicians. Lastly, the survey was conducted in pre-COVID-19 times, so further research on the development of acceptance of telerheumatology use is highly needed.

\section{Comparison With Prior Work}

This work adds to the growing body of telerheumatology knowledge [11-17] by providing detailed user preferences, needs, and barriers. Hence, we believe that the results of this study may help in the development of telemedicine solutions that can be integrated into the clinical routine of patients with rheumatic diseases.

In contrast to the results of a recent study that identified a negative attitude toward digitization in the health care system among physicians in Germany [20], our results indicated that physicians have a positive attitude toward telemedicine. An American Medical Association survey of 3500 physicians in the United States found that fewer than $10 \%$ of rheumatologists used telemedicine, which is significantly less than physicians from other medical fields, such as radiologists (43\%) [21], and less than the percentage of rheumatologists that use telemedicine according to our study (34\%). Although most respondents reckoned that telecounseling may support rheumatology care, telecounseling is not used or is rarely used. In a nationwide survey of digitization among German medical practices, only $1 \%$ of surveyed physicians responded that they use videoconferences to communicate with other physicians. The most frequent answers were email and no digital communication at all [22]. In the survey on digitization in German medical practices, security gaps in information technology (IT), the considerable cost and effort involved in introducing digital technologies, and an unfavorable cost-benefit ratio were identified as the main obstacles to digitization from the perspective of physicians [22]. Participants in our survey attached relatively little importance to security gaps in IT, with only $46.2 \%$ choosing data security as an issue that prevented them from using telemedicine. Televisual consultations with patients appear to have considerable potential in rheumatology care, and especially in initial consultations [12]. However, only a minority of participants in our survey favored the use of telemedicine in initial consultations. This finding confirms the results of a comparable study on veteran rheumatology care from the United States [23]. Furthermore, only one-third of those surveyed wished to use telemedicine in direct patient contacts at all, which contrasts starkly with overall telemedical developments in the health care system [16,17]. This is unfortunate, as previous research has shown that patients with rheumatoid arthritis consider telerheumatology to be a flexible solution that increases the independence of health authorities and raises personal knowledge [24]. Other studies indicate that health care resulting from televisits is as effective as that provided following in-person visits $[25,26]$. A qualitative study also reports that patients would be willing to accept electronic collection and sharing of patient-reported outcomes (PROs) between clinical encounters if it facilitated communication with health care providers and provided access to reliable information on RMDs [27]. However, a recent study has shown that rheumatologists are reluctant to study electronic PROs because it would lead to a massive increase in their workload [28].

Mobile apps promise to accelerate diagnostic investigations and improve monitoring and the outcomes of patients with RMDs [29]. The small number of rheumatologists that supported the use of apps to improve clinical routines (34\%) contrasts with previous research from 2018 in which $49 \%$ said they were already using such apps [30]. One of the top reasons for the reluctance of rheumatologists to use apps may be lack of evidence [31]. The combination of electronic PROs [28] and objective serology and genetic testing promises to result in the earlier diagnosis of RMDs [32].

Our findings indicate that rheumatologists accept telemedicine to a greater extent than general practitioners. Furthermore, the preferences of rheumatologists differ from those of general practitioners with regard to which specific tools could be implemented into rheumatology care and when. These variations may be related to differences in the two professions as well as 
the distinct phases of the disease in which rheumatologists and general practitioners encounter RMDs. We also analyzed differences in the acceptance and preferences of telemedicine with regard to the age and gender of the physicians as well as the type and region of their practices. No differences or only small differences were found.

\section{Perspectives for Telerheumatology}

COVID-19 has demonstrated the importance of contactless approaches in medical care. As early as 2018, when we conducted the survey, rheumatologists and general practitioners were willing to use telerheumatology. It is assumed that this readiness has increased due to the pandemic, which is likely to strongly accelerate the use of telemedicine as society adopts new health care standards [18].

Nevertheless, the great potential of telemedicine is not being fully reached. Further research into the implementation of telerheumatology is desperately needed. This includes large-scale randomized controlled studies on the effects and health economic outcomes, as well as risks and adverse events, of specific interventions.

As our results indicate that there will be no "one-size-fits-all" solution in the realm of telemedicine, further research into the perspectives and preferences of physicians, patients, and other telemedicine users in rheumatology is essential. This may provide the foundation for individual patient- and physician-adapted telemedicine options and triage mechanisms to select patients for either digital or analog consultations, as appropriate $[25,26]$.

As physicians reported barriers to the use of telemedicine, it would appear that the structural framework is not yet in place for the effective implementation of telerheumatology. Considerable administrative effort and inadequate reimbursement structures prevented the surveyed physicians from using telemedicine. However, the greatest barrier was the limited knowledge on the part of physicians on the use of telemedicine, which highlights the need for the timely introduction of low-threshold training courses.

\section{Conclusions}

Our study showed that rheumatologists and general practitioners support the implementation of telerheumatology, and two-thirds of respondents would like to implement telemedicine into their clinical routine. Rheumatologists expressed an even greater willingness to use telemedicine than general practitioners, with respondents welcoming a variety of telemedicine approaches. However, only a minority of the surveyed physicians currently use telemedicine. Furthermore, most physicians regard their knowledge of telemedicine as rather poor. The provision of high-quality rheumatology care using telemedicine will require urgently needed research as well as a reduction in existing barriers and training for specialists and generalists.

\section{Acknowledgments}

The authors would like to thank the participants, their teams, and all other supporters of this study. We also owe special gratitude to KV Consult- und Managementgesellschaft $\mathrm{mbH}$, which initiated the study. We thank Phillip Elliot for editing the manuscript. Financial support was provided by Novartis Pharma GmbH. Novartis had no role in the study design or in the collection, analysis, or interpretation of the data; the writing of the manuscript; or the decision to submit the manuscript for publication. Publication of this article was not contingent upon approval by Novartis.

\section{Authors' Contributions}

All authors were involved in drafting the article and critically revising it for important intellectual content, and all authors approved the final version to be submitted for publication. FM had full access to all the data in the study and takes responsibility for the integrity of the data and the accuracy of the data analysis. FM, WM, and MW were responsible for the study conception and design and for acquisition of the data. FM, JK, WM, JE, AH, and MW were responsible for analysis and interpretation of the data.

\section{Conflicts of Interest}

None declared.

\section{References}

1. Sebbag E, Felten R, Sagez F, Sibilia J, Devilliers H, Arnaud L. The world-wide burden of musculoskeletal diseases: A systematic analysis of the World Health Organization Burden of Diseases Database. Ann Rheum Dis 2019 Jun;78(6):844-848. [doi: 10.1136/annrheumdis-2019-215142] [Medline: $\underline{\text { 30987966] }}$

2. Sullivan PW, Ghushchyan V, Huang X, Globe DR. Influence of rheumatoid arthritis on employment, function, and productivity in a nationally representative sample in the United States. J Rheumatol 2010 Mar;37(3):544-549. [doi: 10.3899/jrheum.081306] [Medline: 20080920]

3. Krusche M, Sewerin P, Kleyer A, Mucke J, Vossen D, Morf H, Rheumadocs und Arbeitskreis Junge Rheumatologie (AGJR). Specialist training quo vadis? [Article in German]. Z Rheumatol 2019 Oct;78(8):692-697. [doi: 10.1007/s00393-019-00690-5] [Medline: 31468164$]$

4. Al Maini M, Adelowo F, Al Saleh J, Al Weshahi Y, Burmester G, Cutolo M, et al. The global challenges and opportunities in the practice of rheumatology: White paper by the World Forum on Rheumatic and Musculoskeletal Diseases. Clin Rheumatol 2015 May;34(5):819-829 [FREE Full text] [doi: 10.1007/s10067-014-2841-6] [Medline: 25501633] 
5. Hobbs FDR, Bankhead C, Mukhtar T, Stevens S, Perera-Salazar R, Holt T, National Institute for Health Research School for Primary Care Research. Clinical workload in UK primary care: A retrospective analysis of 100 million consultations in England, 2007-14. Lancet 2016 Jun 04;387(10035):2323-2330 [FREE Full text] [doi: 10.1016/S0140-6736(16)00620-6] [Medline: 27059888]

6. Ulrich L, Lemke D, Erler A, Müller B, Gerlach F, Dahlhaus A. Work stress among family physicians in two Thuringian districts [Article in German]. Z Allg Med 2019;95:112-118 [FREE Full text] [doi: 10.3238/zfa.2019.0112-0118]

7. Sørensen J, Hetland ML. Diagnostic delay in patients with rheumatoid arthritis, psoriatic arthritis and ankylosing spondylitis: Results from the Danish nationwide DANBIO registry. Ann Rheum Dis 2015 Mar;74(3):e12 [FREE Full text] [doi: 10.1136/annrheumdis-2013-204867] [Medline: 24534758]

8. Quinn M, Emery P. Window of opportunity in early rheumatoid arthritis: Possibility of altering the disease process with early intervention. Clin Exp Rheumatol 2003;21(5 Suppl 31):S154-S157 [FREE Full text] [Medline: 14969068]

9. WMA Statement on the Ethics of Telemedicine. World Medical Association. 2018. URL: https://www.wma.net/policies-post/ wma-statement-on-the-ethics-of-telemedicine/ [accessed 2021-03-05]

10. Ward IM, Schmidt TW, Lappan C, Battafarano DF. How critical is tele-medicine to the rheumatology workforce? Arthritis Care Res (Hoboken) 2016 Oct;68(10):1387-1389 [FREE Full text] [doi: 10.1002/acr.22853] [Medline: 26866514]

11. Rezaian MM, Brent LH, Roshani S, Ziaee M, Sobhani F, Dorbeigi A, et al. Rheumatology care using telemedicine. Telemed J E Health 2020 Mar;26(3):335-340. [doi: 10.1089/tmj.2018.0256] [Medline: 31084537]

12. Leggett P, Graham L, Steele K, Gilliland A, Stevenson M, O'Reilly D, et al. Telerheumatology--Diagnostic accuracy and acceptability to patient, specialist, and general practitioner. Br J Gen Pract 2001 Sep;51(470):746-748 [FREE Full text] [Medline: 11593837$]$

13. Kuusalo L, Sokka-Isler T, Kautiainen H, Ekman P, Kauppi MJ, Pirilä L, SandRA Study Group. Automated text message-enhanced monitoring versus routine monitoring in early rheumatoid arthritis: A randomized trial. Arthritis Care Res (Hoboken) 2020 Mar;72(3):319-325. [doi: 10.1002/acr.23846] [Medline: 30740935]

14. Salaffi F, Carotti M, Ciapetti A, Di Carlo M, Gasparini S, Farah S, et al. Effectiveness of a telemonitoring intensive strategy in early rheumatoid arthritis: Comparison with the conventional management approach. BMC Musculoskelet Disord 2016 Apr 02;17:146 [FREE Full text] [doi: 10.1186/s12891-016-1002-2] [Medline: 27038788]

15. de Thurah A, Stengaard-Pedersen K, Axelsen M, Fredberg U, Schougaard LMV, Hjollund NHI, et al. Tele-health followup strategy for tight control of disease activity in rheumatoid arthritis: Results of a randomized controlled trial. Arthritis Care Res (Hoboken) 2018 Mar;70(3):353-360. [doi: 10.1002/acr.23280] [Medline: 28511288]

16. Piga M, Cangemi I, Mathieu A, Cauli A. Telemedicine for patients with rheumatic diseases: Systematic review and proposal for research agenda. Semin Arthritis Rheum 2017 Aug;47(1):121-128. [doi: 10.1016/j.semarthrit.2017.03.014] [Medline: 28420491]

17. McDougall JA, Ferucci ED, Glover J, Fraenkel L. Telerheumatology: A systematic review. Arthritis Care Res (Hoboken) 2017 Oct;69(10):1546-1557 [FREE Full text] [doi: 10.1002/acr.23153] [Medline: 27863164]

18. Hollander JE, Carr BG. Virtually perfect? Telemedicine for Covid-19. N Engl J Med 2020 Apr 30;382(18):1679-1681. [doi: 10.1056/NEJMp2003539] [Medline: 32160451]

19. Statistical Information From the Federal Register of Physicians [Report in German]. Berlin, Germany: Kassenärztliche Bundesvereinigung; 2020. URL: https://www.kbv.de/media/sp/2020-12-31 BAR Statistik.pdf [accessed 2021-03-23]

20. Hansen A, Herrmann M, Ehlers JP, Mondritzki T, Hensel KO, Truebel H, et al. Perception of the progressing digitization and transformation of the German health care system among experts and the public: Mixed methods study. JMIR Public Health Surveill 2019 Oct 28;5(4):e14689 [FREE Full text] [doi: 10.2196/14689] [Medline: 31661082]

21. Kane CK, Gillis K. The use of telemedicine by physicians: Still the exception rather than the rule. Health Aff (Millwood) 2018 Dec;37(12):1923-1930. [doi: 10.1377/hlthaff.2018.05077] [Medline: 30633670]

22. Praxisbarometer Digitalisierung 2019. Stand und Perspektiven der Digitalisierung in der vertragsärztlichen und -psychotherapeutischen Versorgung [Report in German]. Berlin, Germany: Kassenärztliche Bundesvereinigung; 2019. URL: https://www.kbv.de/media/sp/KBV_Praxisbarometer_Digitalisierung_2019.pdf [accessed 2021-03-19]

23. Matsumoto RA, England BR, Mastarone G, Richards JS, Chang E, Wood PR, et al. Rheumatology clinicians' perceptions of telerheumatology within the veterans health administration: A national survey study. Mil Med 2020 Dec 30;185(11-12):e2082-e2087. [doi: 10.1093/milmed/usaa203] [Medline: 32789463]

24. Knudsen LR, de Thurah A, Lomborg K. Experiences with telehealth followup in patients with rheumatoid arthritis: A qualitative interview study. Arthritis Care Res (Hoboken) 2018 Sep;70(9):1366-1372. [doi: 10.1002/acr.23483] [Medline: 29195011]

25. Kulcsar Z, Albert D, Ercolano E, Mecchella JN. Telerheumatology: A technology appropriate for virtually all. Semin Arthritis Rheum 2016 Dec;46(3):380-385. [doi: 10.1016/j.semarthrit.2016.05.013] [Medline: 27395561]

26. Taylor-Gjevre R, Nair B, Bath B, Okpalauwaekwe U, Sharma M, Penz E, et al. Addressing rural and remote access disparities for patients with inflammatory arthritis through video-conferencing and innovative inter-professional care models. Musculoskeletal Care 2017 Oct 02;16(1):90-95. [doi: 10.1002/msc.1215] [Medline: 28967235] 
27. Navarro-Millán I, Zinski A, Shurbaji S, Johnson B, Fraenkel L, Willig J, et al. Perspectives of rheumatoid arthritis patients on electronic communication and patient-reported outcome data collection: A qualitative study. Arthritis Care Res (Hoboken) 2019 Jan;71(1):80-87 [FREE Full text] [doi: 10.1002/acr.23580] [Medline: 29669191]

28. Krusche M, Klemm P, Grahammer M, Mucke J, Vossen D, Kleyer A, et al. Acceptance, usage, and barriers of electronic patient-reported outcomes among German rheumatologists: Survey study. JMIR Mhealth Uhealth 2020 Jul 20;8(7):e18117 [FREE Full text] [doi: 10.2196/18117] [Medline: 32390592]

29. Krusche M, Ruffer N, Grahammer M, Knitza J. Mobile apps and their usage in rheumatology [Article in German]. Z Rheumatol 2020 Aug;79(6):554-561. [doi: 10.1007/s00393-020-00822-2] [Medline: 32472178]

30. Knitza J, Vossen D, Geffken I, Krusche M, Meyer M, Sewerin P, Arbeitskreis Junge Rheumatologen. Use of medical apps and online platforms among German rheumatologists: Results of the 2016 and 2018 DGRh conference surveys and research conducted by rheumadocs [Article in German]. Z Rheumatol 2019 Nov;78(9):839-846. [doi: 10.1007/s00393-018-0578-3] [Medline: $\underline{30542914]}$

31. Knitza J, Tascilar K, Messner E, Meyer M, Vossen D, Pulla A, et al. German mobile apps in rheumatology: Review and analysis using the Mobile Application Rating Scale (MARS). JMIR Mhealth Uhealth 2019 Aug 05;7(8):e14991 [FREE Full text] [doi: 10.2196/14991] [Medline: 31381501]

32. Knitza J, Knevel R, Raza K, Bruce T, Eimer E, Gehring I, JPAST Group. Toward earlier diagnosis using combined eHealth tools in rheumatology: The Joint Pain Assessment Scoring Tool (JPAST) project. JMIR Mhealth Uhealth 2020 May 15;8(5):e17507 [FREE Full text] [doi: 10.2196/17507] [Medline: 32348258]

\author{
Abbreviations \\ IT: information technology \\ PRO: patient-reported outcome \\ RHADAR: RheumaDatenRhePort GbR \\ RMD: rheumatic and musculoskeletal disease \\ Telerheumatology: telemedicine in rheumatology
}

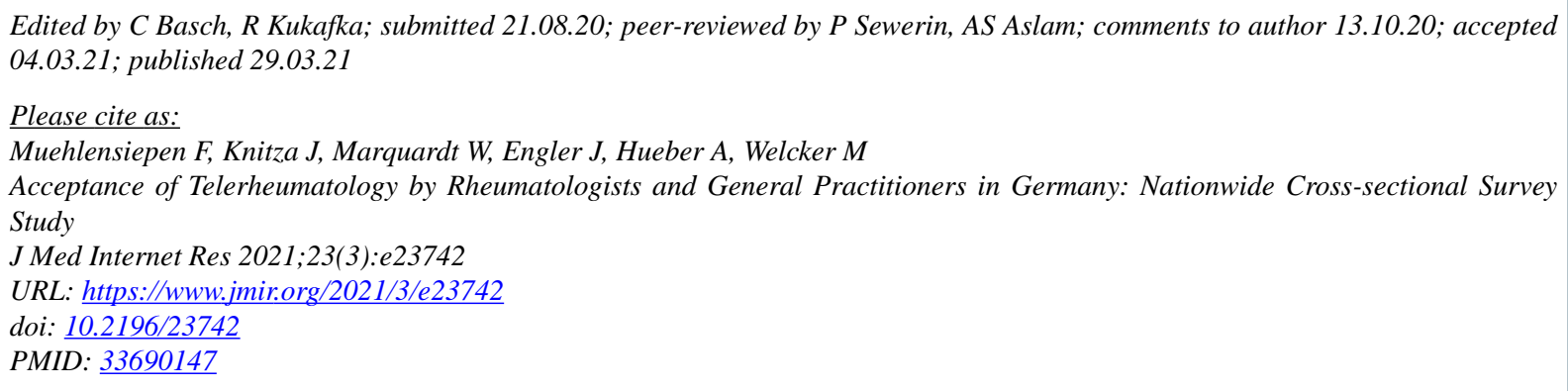

CFelix Muehlensiepen, Johannes Knitza, Wenke Marquardt, Jennifer Engler, Axel Hueber, Martin Welcker. Originally published in the Journal of Medical Internet Research (http://www.jmir.org), 29.03.2021. This is an open-access article distributed under the terms of the Creative Commons Attribution License (https://creativecommons.org/licenses/by/4.0/), which permits unrestricted use, distribution, and reproduction in any medium, provided the original work, first published in the Journal of Medical Internet Research, is properly cited. The complete bibliographic information, a link to the original publication on http://www.jmir.org/, as well as this copyright and license information must be included. 